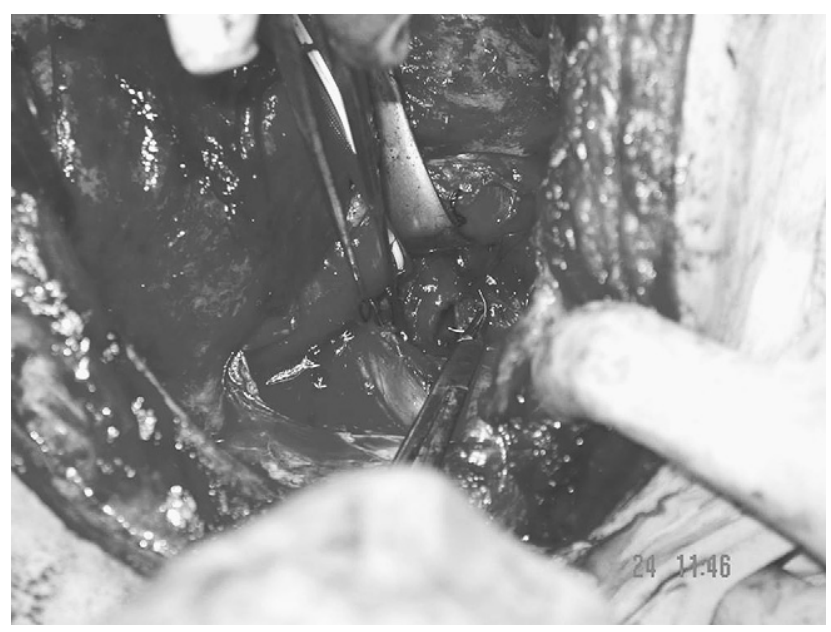

FIGURE 2. Anastomosis of the left main bronchus to tracheocarinal level above the aortic arch and in front of the esophagus.

induce inflammation and edema; therefore, serious endoluminal obstruction may occur. Recurrent suppurative pneumonia can occur due to obstruction. Our patient aspirated a chicken bone 4 years previously and underwent several rigid bronchoscopy attempts to extract the foreign body. She was admitted to the Istanbul Medical School after an episode of pneumonia and had dyspnea and audible wheezing because of near total airway obstruction diagnosed via bronchoscopy. Ibrahim Sersar and colleagues ${ }^{2}$ reported a series of 3300 patients, 3 of whom required bronchotomy because extraction of the inhaled foreign body failed. ${ }^{2}$ In another study, ${ }^{4} 164$ patients underwent bronchoscopy for foreign body aspiration, and $6 \%$ of patients required surgical extraction. Early bronchoscopy has high successful rates in the extraction of foreign bodies. Bronchotomy is usually enough to extract the foreign body, which was performed after early bronchoscopy. Because of the delay in extraction, our patient required an extended operation, a segmental main bronchial resection with supra-aortic anastomosis. After unsuccessful attempts, a bronchotomy would have been a less-invasive procedure for this patient. Thus, we advise an early operation for organic foreign bodies.

\section{CONCLUSIONS}

Early diagnosis of foreign body aspiration depends on high clinical suspicion, clinical signs, and radiologic findings. It is important to extract the foreign body via an early endoscopy or a surgical approach because retained organic foreign bodies may cause severe anatomic problems in the airways and require complicated surgical procedures.

\section{References}

1. Pinzoni F, Boniotti C, Molinaro SM, Baraldi A, Berlucchi M. Inhaled foreign bodies in pediatric patients: review of personal experience. Int J Pediatr Otorhinolaryngol. 2007;71:1897-903.

2. Ibrahim Sersar S, Hamza UA, AbdelHameed WA, AbulMaaty RA, Gowaeli NN Moussa SA, et al. Inhaled foreign bodies: management according to early or late presentation. Eur J Cardiothorac Surg. 2005;28:369-74.

3. Debeljak A, Sorli J, Music E, Kecelj P. Bronchoscopic removal of foreign bodies in adults: experience with 62 patients from 1974-1998. Eur Respir J. 1999;14:792-5.

4. Cataneo AJ, Cataneo DC, Ruiz Jr RL Management of tracheobronchial foreign body in children. Pediatr Surg Int. 2008;24:151-6; Epub 2007 Nov 6.

\title{
A successful neonatal repair of congenital aortic aneurysm with cleft sternum
}

\author{
Yasutaka Hirata, MD, ${ }^{a}$ Marc S. Arkovitz, MD, ${ }^{\mathrm{b}}$ Charles C. Marboe, MD,${ }^{\mathrm{c}}$ and Ralph S. Mosca, MD, ${ }^{\mathrm{a}}$ New York, NY
}

\footnotetext{
From the Divisions of Cardiothoracic Surgery, ${ }^{\mathrm{a}}$ Pediatric Surgery, ${ }^{\mathrm{b}}$ and Pathology, Department of Surgery, Columbia University College of Physicians and Surgeons, New York, NY.

Received for publication Dec 5, 2007; revisions received April 25, 2008; accepted for publication June 21, 2008.

Address for reprints: Yasutaka Hirata, MD, The Division of Pediatric Cardiac Surgery, Columbia University College of Physicians and Surgeons, New York, NY (E-mail: yh2240@columbia.edu).

J Thorac Cardiovasc Surg 2009;137:769-71

$0022-5223 / \$ 36.00$

Copyright (c) 2009 by The American Association for Thoracic Surgery

doi:10.1016/j.jtcvs.2008.06.037
}

Thoracic aortic aneurysm is rare in the pediatric age group; only a few cases have been described and are often associated with connective tissue disorders such as Marfan or Ehlers-Danlos syndrome ${ }^{1}$ or coarctation of the aorta. ${ }^{2}$ The association of aortic aneurysm with a sternal defect in infants or children has been previously reported on only 3 occasions. ${ }^{3-5}$ Although the long-term morbidity is unknown, 2 of the 3 patients had either progressive dilation ${ }^{4}$ or rupture ${ }^{5}$ of the aneurysm. We report a successful repair of congenital aortic aneurysm and cleft sternum in a neonate. 


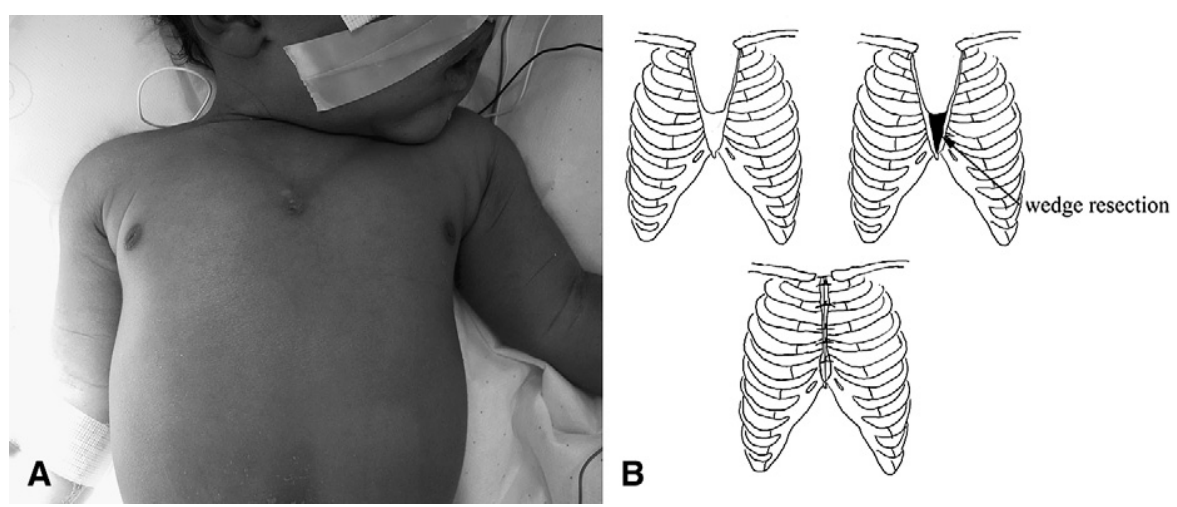

FIGURE 1. A, Upper part of the sternum is defective. B, Wedge resection of the sternum to approximate the cleft.
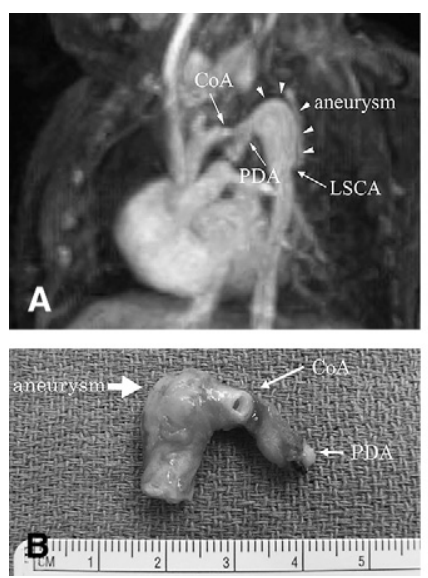

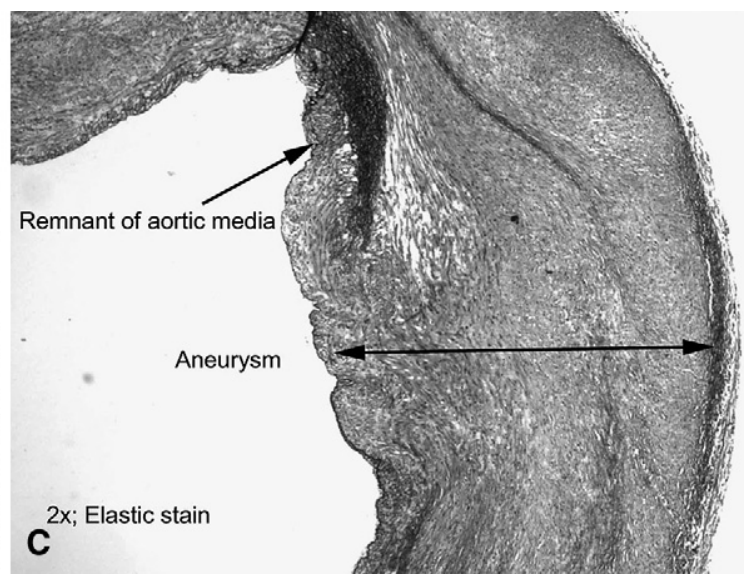

FIGURE 2. A, Magnetic resonance image of the thoracic aortic aneurysm. CoA, coarctation; $P D A$, patent ductus arteriosus; $L S C A$, left subclavian artery. B, Resected aneurysm (seen from back). C, Histologic examination of the aneurysm.

\section{CLINICAL SUMMARY}

The patient was referred to our hospital with a fetal diagnosis of aortic aneurysm and deficient upper chest wall. She was born by elective cesarean section at 39 weeks of gestation. Upper sternal cleft was noted (Figure 1) through which soft tissue would extrude during respiration. Echocardiography and magnetic resonance imaging revealed a significant aortic arch aneurysm with a moderate coarctation located just proximal to the aneurysm (Figure 2, $A$ ).

The skin was opened in the midline. The lower quarter of the sternum, which was intact, was opened with a sternal saw. The pericardium was completely intact and was opened in the midline. She was systemically heparinized and placed on cardiopulmonary bypass with ascending aortic and right atrial cannulation and cooled to $18^{\circ} \mathrm{C}$. The ductus was doubly ligated and divided. The ascending aorta, head vessels, transverse arch, and descending thoracic aorta were widely mobilized to facilitate the repair. The left subclavian artery was displaced inferiorly and laterally approximately $2.5 \mathrm{~cm}$ from the left common carotid artery. The aneurysm measured approximately $3 \mathrm{~cm}$ at its widest point. A period of circulatory arrest was used during the reconstruction. The aorta was divided just proximal to the aortic aneurysm tissue, which was just distal to the left common carotid artery. The entire aneurysm was excised (Figure 2, $B$ ).

The proximal transverse arch was beveled to the mid ascending aorta and a counterincision was also made in the distal part of the descending aorta. A pulmonary allograft patch was sewn to augment the undersurface of the aorta. The circulatory arrest time was 32 minutes.

The sternum was repaired primarily. So that the upper portions of the chest wall could be closed, a bevel was taken out of the inferior aspect of the sternum. After this, the inferior edges were able to meet in the midline without overlapping and the upper portions could be approximated. The sternal repair was performed with No. 2 interrupted wires. The upper two wires were placed through the medial portions of the ribs (Figure 1,B).

Microscopic examination of the aneurysmal aortic wall demonstrated an apparently dysplastic aorta with irregularly 
distributed elastic tissue, smooth muscle, and myointimal cells (Figure 2, C). There appeared to be a smaller portion of tissue, likely ductus with intimal proliferation.

Except for some feeding difficulties, the patient's postoperative course was uneventful and she was discharged 3 weeks after the operation.

\section{DISCUSSION}

Although rare in childhood, aneurysms of the thoracic aorta have been reported in infants and children in association with the Mafan or Ehlers-Danlos syndrome ${ }^{1}$ or coarctation of the aorta. ${ }^{2}$ The combination of aortic aneurysm and sternal cleft has been reported three times, including a case as a part of the PHACE syndrome (posterior fossa brain malformations, hemangiomas, arterial anomalies, coarctation of the aorta and cardiac defects, and eye abnormalities). ${ }^{5}$ Although the long-term morbidity and mortality of the aneurysm is unknown, 2 patients had either progressive dilation $^{4}$ or rupture ${ }^{5}$ of the aneurysm. Operation was undertaken for the following three reasons: (1) to relieve the coarctation of the aorta proximal to the aneurysm, (2) to prevent possible aortic rupture, and (3) to correct the sternal cleft to protect the intrathoracic organs and improve respiratory mechanics. The operation was successful without morbidity. We believe early surgical intervention may be important to avoid dilation and rupture of the aneurysm.

Preoperative magnetic resonance imaging played an important role in delineating the extent of the aortic disease.
The aneurysm started after the left common carotid artery and extended to the origin of the left subclavian artery. Although it is difficult to differentiate a true aortic aneurysm from "ductal aneurysm," the resected specimen showed normal size of the ductus arteriosus itself (Figure 2, $B$ ). In addition, the fact that the aneurysm "ended before" the origin of the left subclavian artery leads us to believe that this is a true aortic aneurysm inasmuch as a ductal aneurysm is a continuation of the ductus arteriosus, which most often connects with and extends into the aortic isthmus "after" the origin of the left subclavian artery.

In summary, we reported our experience with the successful repair of a rare association in a neonate with sternal cleft and thoracic aortic aneurysm.

\section{References}

1. Conte S, Serraf A, Lacour-Gayet F, Brunjaux J, Planche C. Successful repair of thoracic aortic aneurysm in a child with Ehlers-Danlos syndrome. J Thorac Cardiovasc Surg. 1997;113:410-1.

2. Fricker FI, Park SC, Neches WH, Mathews RA, Lerberg DB. Aneurysm of the aorta in children. Chest. 1979;76:305-9.

3. Raas-Rothschild A, Nir A, Gillis R, Rein AJ. Giant congenital aortic aneurysm with cleft sternum, supraumbilical raphe, and hemangiomatosis: report and review. Am J Med Genet. 2000;90:243-5.

4. Schieken LS, Brenner JI, Baker KR, Ringel RE, Pacifico A. Aneurysm of the ascending aorta associated with sternal cleft, cutaneous hemangioma, and occlusion of the right innominate artery in a neonate. Am Heart J. 1987;113: 202-4.

5. Slavotinek AM, Dubovsky E, Dietz HC, Lacbawan F. Report of a child with aortic aneurysm, orofacial clefting, hemangioma, upper sternal defect, and marfanoid features: possible PHACE syndrome. Am J Med Genet. 2002;110:283-8.

\title{
Successful bilateral lung transplant from a donor with a tracheal right upper lobe bronchus
}

\author{
Jeroen M. H. Hendriks, PhD, Ivo Deblier, MD, Bjorn Dieriks, MD, Annelies Janssens, MD, Willy Coosemans, PhD,
} Pieter ten Broecke, MD, and Paul Van Schil, PhD, Edegem and Leuven, Belgium

A successful bilateral sequential lung transplant for endstage emphysema was performed with a right upper tracheal bronchus in the donor. No anastomotic complications were

\footnotetext{
From the Departments of Thoracic and Vascular Surgery, Cardiac Surgery, Pulmonary Medicine, and Anesthesiology, University Hospital Antwerp, Edegem, Belgium, and the Department of Thoracic Surgery, University of Leuven Gasthuisberg, Leuven, Belgium.

Received for publication Dec 7, 2007; accepted for publication Dec 13, 2007.

Address for reprints: Jeroen M. H. Hendriks, PhD, Thoracic and Vascular Surgery, University Hospital Antwerp (UZA), Nicolaas Lemmensstraat, Wilrijkstraat 10, 2650 Edegem, Belgium (E-mail: jeroen.hendriks@uza.be).

J Thorac Cardiovasc Surg 2009;137:771-3

0022-5223/\$36.00

Copyright (C) 2009 by The American Association for Thoracic Surgery

doi:10.1016/j.jtcvs.2007.12.083
}

encountered, demonstrating that a successful transplant with this congenital anomaly is possible.

\section{CLINICAL SUMMARY}

The recipient was a 57-year-old male patient with endstage emphysema. With a forced expiratory volume in $1 \mathrm{sec}-$ ond of $0.63 \mathrm{~L}$ and a forced vital capacity of $1.74 \mathrm{~L}$, he was listed for bilateral lung transplant in May 2006. On October 15,2006 , a suitable donor was found. Radiographs showed no abnormalities, and gas exchange was excellent $\left(\mathrm{PO}_{2} 396\right.$ $\mathrm{mmHg}$ with inspired oxygen fraction of $40 \%$ ). Before lung retrieval, bronchoscopy discovered a tracheal bronchus for the right upper lobe (Figure 1). 